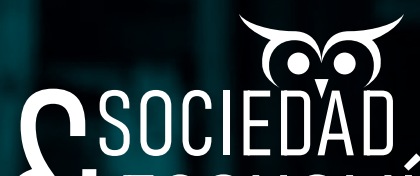 ¿ECONOMÍA
}

$\mathbf{N}^{\circ} 42$

Ene - Abr 2021

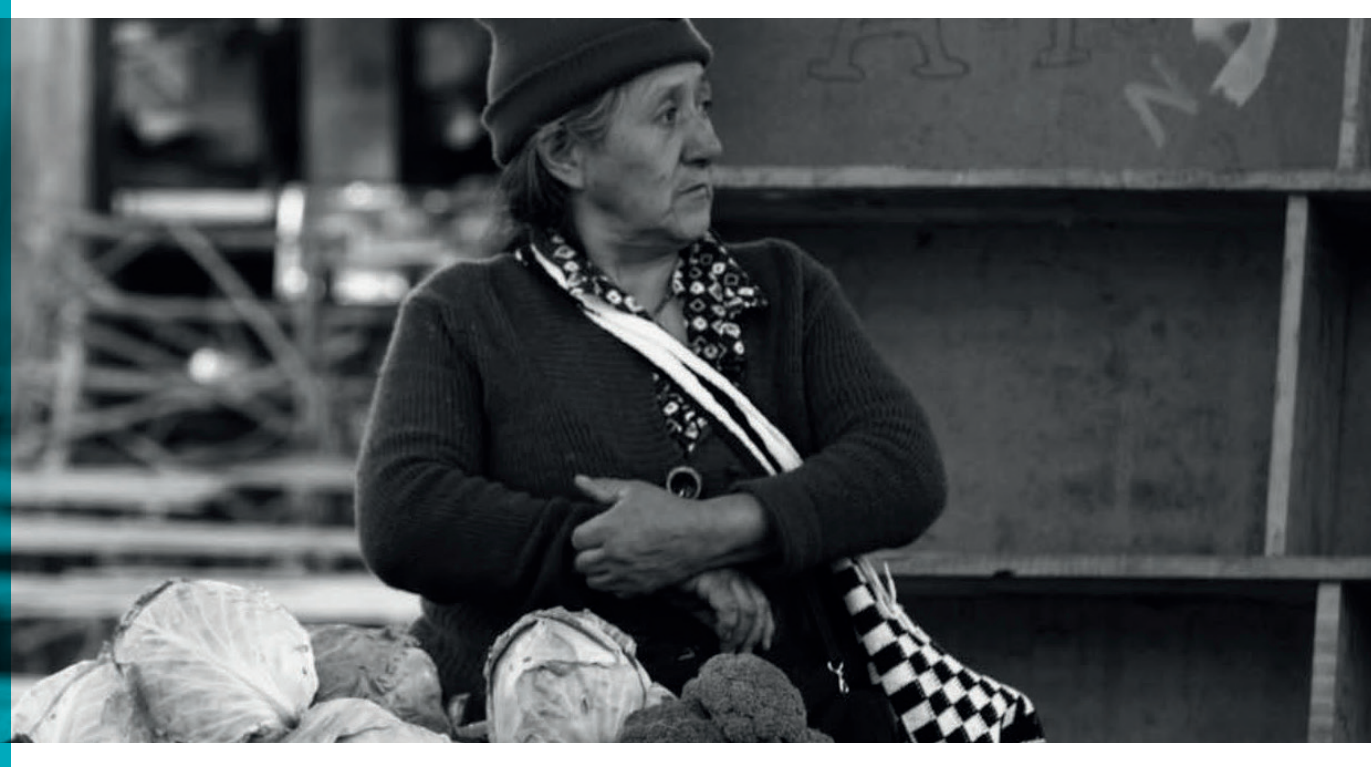

\section{The Banana Leaf Approach: An Appreciation of Utilitarian Handcrafted Artifacts in the American Context}

El enfoque de la hoja de plátano: una apreciación de los artefactos artesanales utilitarios, en el contexto americano

Rafael Ángel-Bravo'

Corporación Universitaria Autónoma de Nariño -AUNAR-, Cali, Colombia.

실 angelrafael1980@hotmail.com

(D) https://orcid.org/0000-0001-6326-6787
Received: 02-07-2020 Accepted: 09-10-2020 Published: 15-04-2021

1 Máster en Comunicación Empresarial y Corporativa. 


\begin{abstract}
There is a whole wide diversity regarding how people adapt to the natural environment conditions and how they value or relate to their everyday objects and products; outside aesthetics or functionality, users appreciate utilitarian artifacts according to assorted perspectives and factors, including traditional, emotional, and cultural approaches. This paper is envisioned to propose a reflection regarding the value and significance of utilitarian handcrafted objects as a fundamental element of popular culture, associated with tradition, heritage, and folkloric preservation. Based on direct experience, photographic record, and assorted theoretical approaches, it was viable to generate a conceptual review and reflection considering the consumers' appreciation of traditional handcrafted artifacts, understanding these implements' value and significance beyond their form and function, as the cultural significance of handcrafted utilitarian, decorative and traditional products, as a crucial component of tangible and intangible heritages and identities in the American context.

Keywords: folklore; handicraft; cultural identity; traditional knowledge; rural development.
\end{abstract}

\title{
Resumen
}

Existe gran diversidad respecto a cómo las personas se adaptan a las condiciones del entorno natural y cómo se relacionan con sus objetos y productos cotidianos. Por encima de su estética y su funcionalidad, los usuarios valoran los artefactos utilitarios de acuerdo con diversas perspectivas y factores, incluyendo aproximaciones tradicionales, emocionales y culturales. Este artículo busca proponer una reflexión frente al valor de los artefactos utilitarios y artesanales, como elemento fundamental de la cultura popular, asociado a la tradición, el patrimonio y el folklore. Con base en la experiencia directa, registro fotográfico y diversas aproximaciones teóricas, fue posible proponer una revisión conceptual y una reflexión frente a la apreciación de los consumidores hacia sus artefactos cotidianos, más allá de la forma y la función, como el significado de los artículos artesanales y tradicionales, decorativos o utilitarios, componentes fundamentales de la identidad y el patrimonio material e inmaterial, en el contexto americano.

Palabras clave: folklore; artesanía; identidad cultural; conocimientos tradicionales; población rural.

\section{Funding}

Research project funded by the Corporación Universitaria Autónoma de Nariño AUNAR, Cali.

\section{Conflict of Interest}

The author declares that there is no conflict of interest. 


\section{Introduction}

There is a whole considerable diversity regarding how agrarian and peasant societies adapt to the natural environment conditions and how they value or relate to their everyday objects, products, tools, and artifacts. Through the history of mankind, these communities have been forced to adapt to their natural environment, solving everyday problems, transforming resources like plants, leaves, woods, vegetal fibers, and assorted materials into artifacts, tools, packages, containers, and other utilitarian products, satisfying their essential needs and facilitating everyday activities, as seen in Figure 1. Additionally, handcrafted objects have been used for omen, ritual, spiritual, superstitious, or merely entertaining purposes. This way, the human being uses the natural resources at his disposal and valuates common objects, for a wide range of reasons beyond beauty or efficiency, including cultural, emotional, spiritual, and mystical connections between consumers and products.

In 2011, assuming what Charles Eames defined as "The uncommon beauty of common things" as its underlying subject, the Architecture + Design Museum in Los Angeles opened its doors for the exhibit Eames' Words: The Guest Host Relationship, inspired by Charles and Ray Eames' words and ideas, emphasizing the importance and beauty of everyday objects for people's lives, like these designers' ability to anticipate users' needs, featuring toys, foods, tools, furniture, vehicles and functional objects. This selection was accompanied by a compilation of the Eames team's statements, exalting and decontextualizing a series of utilitarian implements, appreciating the beauty behind those simple everyday objects that make people's lives easier and constitute an essential component for societies and cultures' evolution (Cruger, 2012).

Through an extensive and diverse body of collaborative work, including industrial design, architecture, literature, and movies, Charles and Ray Eames developed a concept about beauty, functionality, and other standards regarding product design, relations between artifacts and users, as the importance of objects in habitual activities and moments, including ritual paraphernalia, packaging, alimentary heritage, toys, and handcrafted instruments. Beyond the Eames' utilitarian design icons' beauty and efficiency, their vision about aesthetics, functionality, and the appreciation of things as a prominent component of oral tradition, popular culture, folklore, heritage, development of agrarian societies, and other sociocultural phenomena, was materialized and communicated through their films and theoretical concepts. As explained by Koenig (2015), documentary projects like Day of the Dead, Tops, Bread, Toccata for Toy Trains, or the unreleased Banana Leaf movie from 1972, based on their previous eponymous parable, have become a fundamental testimony of the team's conception about form, function and the user's relation with everyday handcrafted artifacts and products, as these elements achieve iconic status and a valuation beyond the satisfactory concretion of primary human needs.

The purpose of this paper is to motivate a discussion regarding how users, especially in agrarian or peasant societies, adapt to the wild conditions of the environment as they exploit and transform the natural resources of the geographical contexts. Through this analysis it is possible to understand the value and significance of common everyday objects beyond their aesthetics and functionality as a fundamental element of popular culture, associated with tradition, heritage and folkloric preservation, in times of modernity and globalization. Finally, this paper will address the idea of a particular aesthetic and beauty within everyday handcrafted artifacts and the cultural significance of the organic materials, natural fibers, and raw textures involved in the manufacturing process.

This reflection is supported by direct experience and personal observation, photographic record, and assorted theoretical studies, including Charles and Ray Eames' participatory work and vision, a creative approach that has gone way beyond the utility-vs-beauty debates and discussions. Special emphasis is placed on Charles Eames' Banana leaf parable (as cited in 
Figure 1. Luffa, calabash fruits, wicker, and other vegetable fibers are transformed into utilitarian handcrafted home artifacts. Pasto, Colombia.

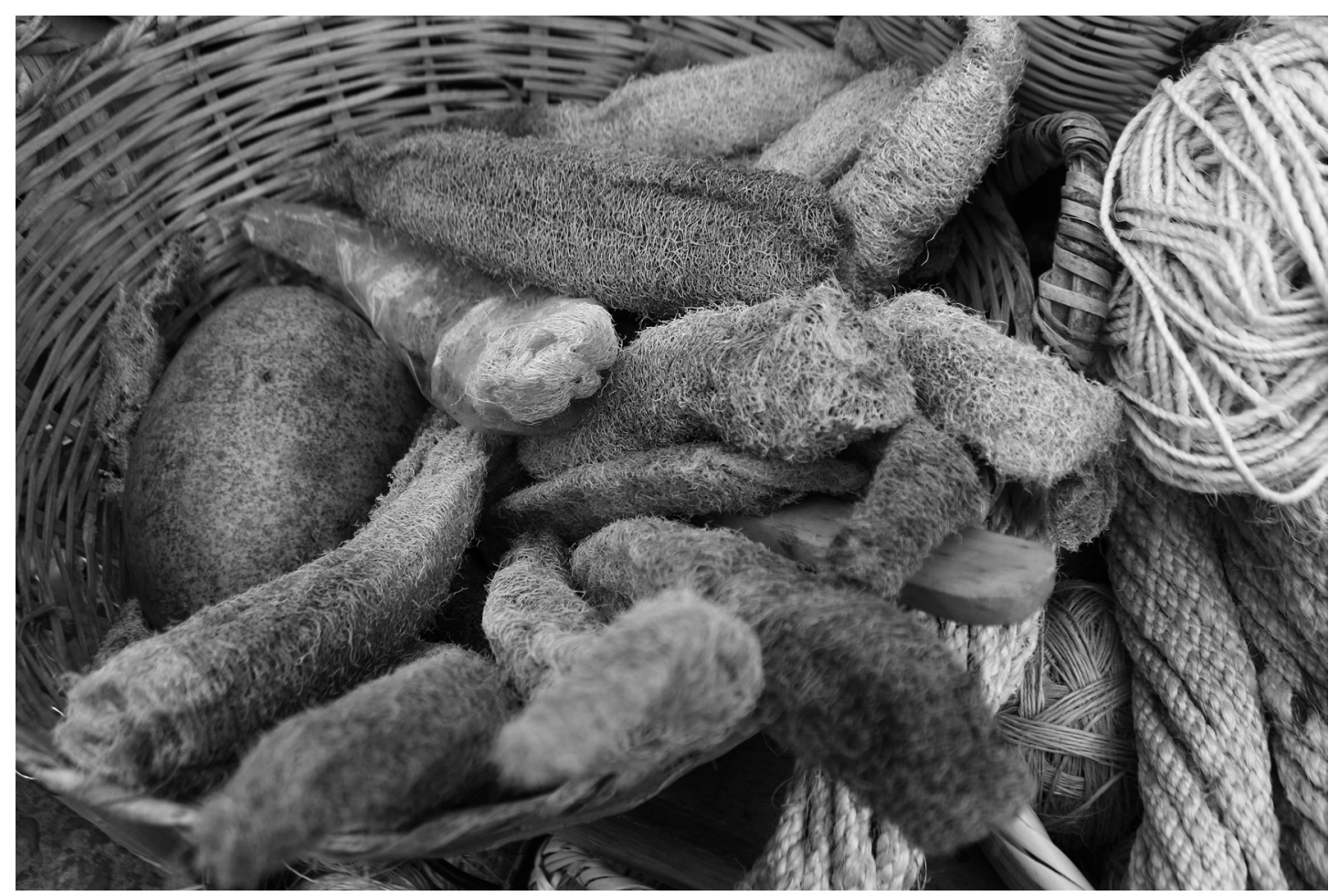

Source: own creation, 2018.

Koenig, 2015, p. 83; Steinberg, 2017), a concept that can be understood and interpreted from dissimilar perspectives, but essentially describes the team's collaborative work in design, architecture, and documentary production. The Eameses' parable and documentary work help to understand their vision concerning product design, functionality, and the relation between users and everyday artifacts.

\section{Functionality Versus Aesthetics}

Herder (as cited in Pulos, 1983) suggested the idea of a distance between fine arts and popular arts, denoting that "(...) man-made forms must be respected according to their devotion to human needs before they may be revered as aesthetic expression (...)" (p. 12). Implying that daily arts and folk expressions should preserve their innocence and simplicity as "(...) any attempt to transform them into fine art destroys the eloquent fragility that gave them their value in the first place (...)" (Herder, as cited in Pulos, 1983, p. 12) preserving their significance as long as they stay pure and unaltered by mass production.

Following a similar approach, Yanasi (as cited in Villegas, 1988) proposes a difference between purely decorative pieces of fine arts and handcrafted utilitarian artifacts or instruments, exemplified in Figure 2:

One of the differences between arts and handcrafts is that people hang their pictures right there, upon the walls. Meanwhile, they put their everyday objects up-close and grab them with their hands. Their beauty resides in its warmness and familiarity (p. 7).

Coinciding with Villegas' (1988) concept of beauty, Franklin (as cited in Pulos, 1983) had 


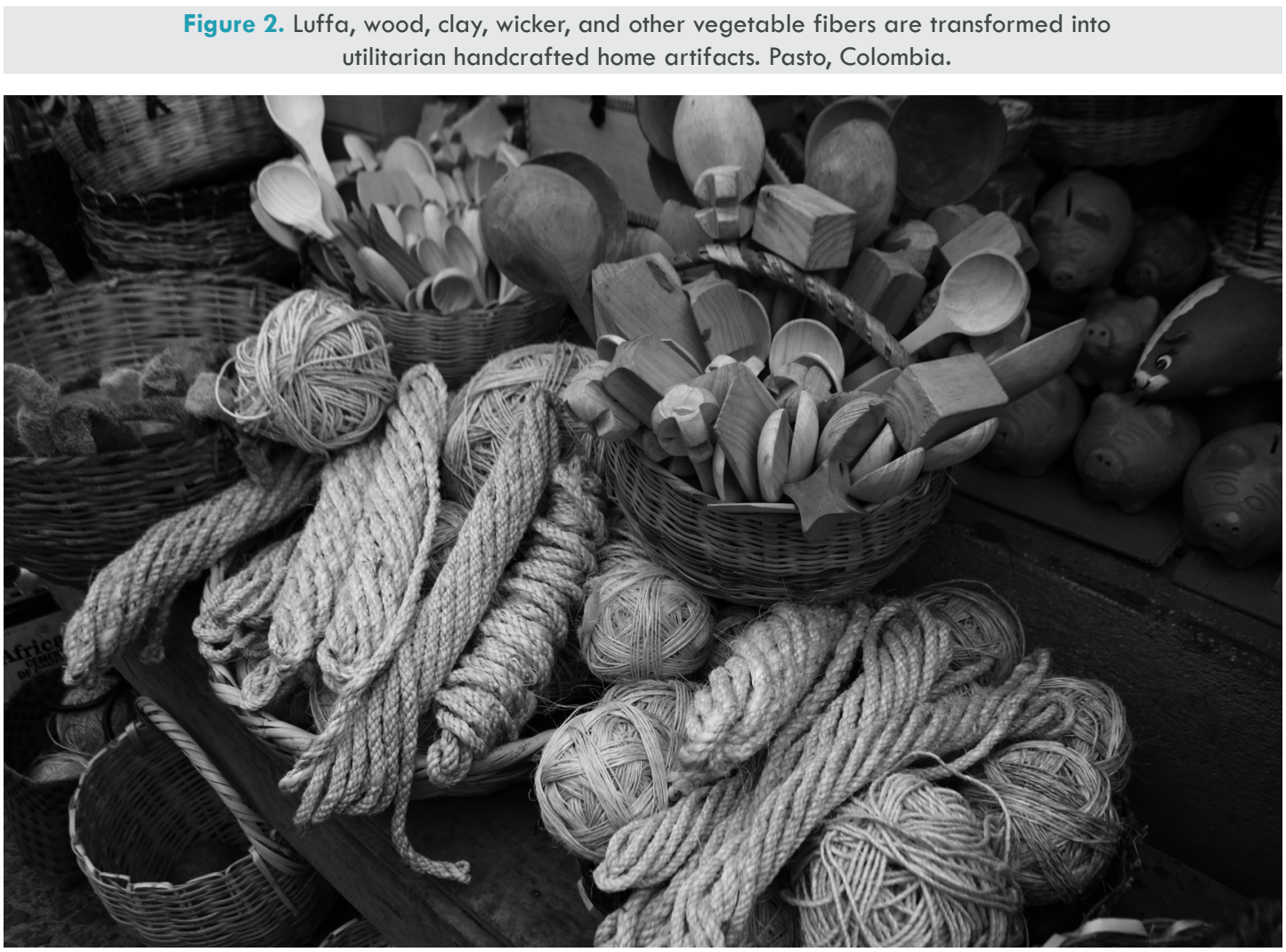

Source: own creation, 2018.

anticipated the idea of functionalism, as "(...) the relation of beauty to utility" (p. 7); according to the American Founding Father "(...) the invention of a machine or the improvement of an implement is of more importance than a masterpiece of Raphael. (...) Nothing is good or beautiful but in the measure that is useful (...)" (Franklin, as cited in Pulos, 1983, p. 7), implying that utilitarian artifacts can be considered more valuable than artwork, hence only what works and fulfills its function, can be considered beautiful. As stated by Pulos (1983):

(...) whatever esthetic reward the American was to derive from his products had to be found in the economy of means and the purification of form to purpose and from the soundness of proportion and the clarity of symbolic form that inevitably result (p. 7).

Following a similar approach, as proposed by Eames \& Eames (2015) the most significant value, regarding utilitarian man-made tools or artifacts, was their functionality and capability of fulfilling their particular purpose, associating any design process with the development of any functional solution. As exposed by the authors:

The problem of designing anything is in a sense the problem of designing a tool. And as in designing a tool, it is usually wise to have a pretty clear idea of what you want the thing to do. The need it is to fill, its particular objective (Eames \& Eames, 2015, p. 115).

As Pulos (1983) explains, from the early stages of the continent's colonization, American natives started performing euthenics, a practice defined by the author as "(...) the development of human well-being and efficient functioning through the improvement of the environment (...)" (p. 7). On the other hand, colonists were struggling to survive and adapt themselves to the New World's wild and hostile natural conditions, creating utilitarian solutions for their ordinary activities (Figure 
3), as opposed to the opulence and ornamental extravagances of their previous lifestyles in Europe, as described by Pulos (1983). According to Villa-Carmona (2005), among these peasant societies, for the artisan "(...) the blueprint of the design resides in his mind, in his ancestral memory (...)" (p. 11), there is no perceptible distinction between designing and manufacturing processes, as users conceive and materialize solutions for their everyday problems, as opposed to later industrialized societies, where design and manufacturing are separated and delimited activities.

Regarding the idea of a balance between form and function, according to Hogarth (1753), "in nature's machines, how wonderfully do we see beauty and use go hand in hand", suggesting that ornaments or any "exquisite beauty of form" (p. 133), must never interfere with any object's movement and function. As proposed by Pulos (1983) the design is concerned with the humane quality of this artificial or man-made environment; therefore, there could be considered a "(...) direct correlation between that quality and the elegance of the form that it takes (...)" (p. 7). As stated by Hogarth (1753), there must be contemplated a "(...) curious difference between the fitness of nature's machines (...) and those made by mortal hands" (p. 133), proposing a distinction between natural vegetal, animal, and human structures, against artificial or man-made artifacts.

According to Eames \& Eames (2011), "what works good is better than what looks good, the looks good can change, but what works, works" (n.p.), evidencing the artists' focus on functionality over aesthetics and beauty, as a permanent, timeless, and transcendent factor considering utilitarian objects, regardless of trends, styles, and movements. When asked to choose between beauty and functionality, Eames \& Eames (2015) notoriously expressed " (...) I should make a choice between keeping my head or my heart?" ( $p$. 95), pointing out the importance of beauty and

Figure 3. Banana and plantain leaves are used as a surface and packaging material for assorted foods in rural communities. San Andrés, Colombia.

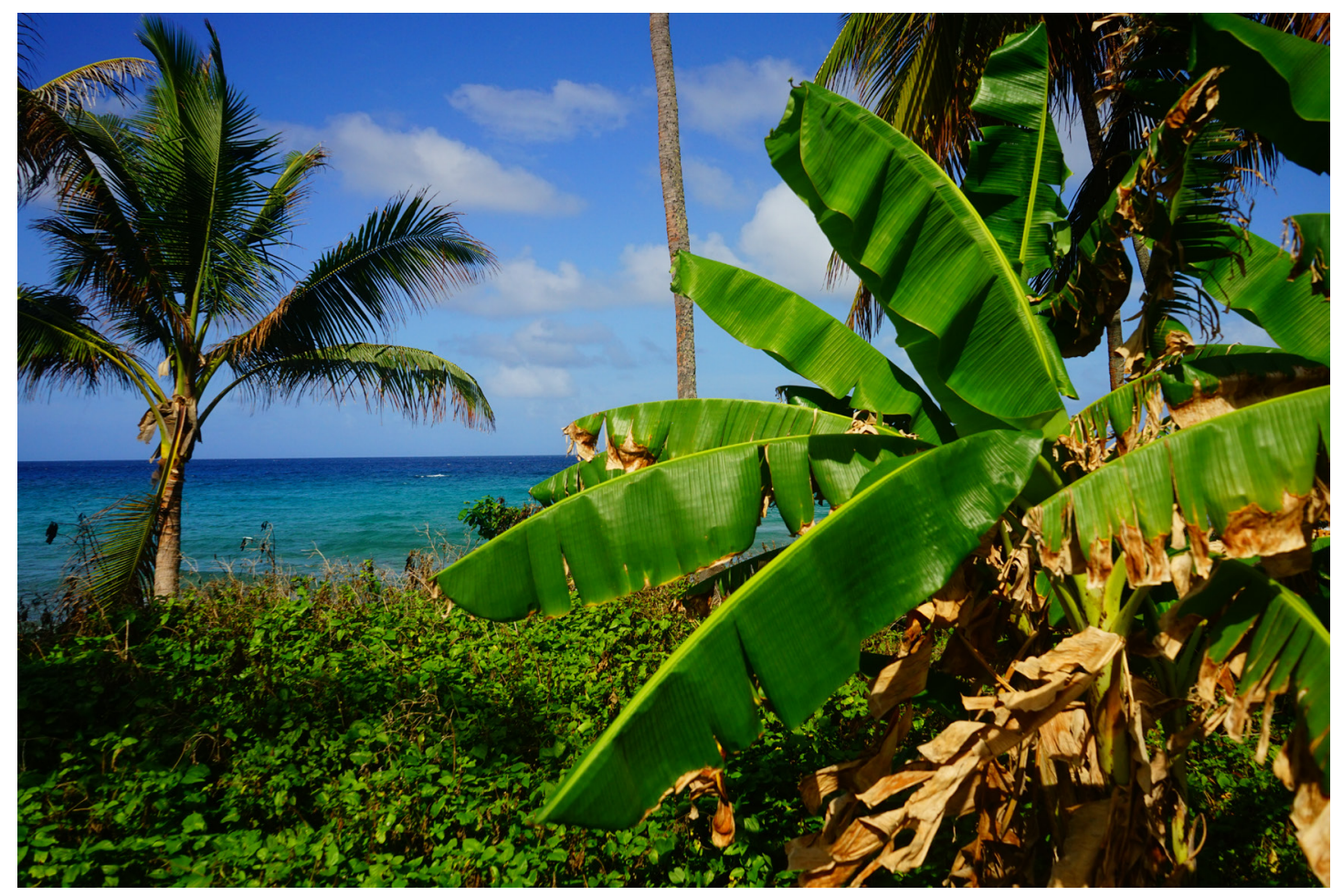


utility as closely correlated factors concerning an object and proposing utility as a crucial condition behind aesthetics, understanding utility as a rational understanding and beauty as an emotional relation between users and their everyday artifacts.

Eames \& Eames' views about common utilitarian objects and their functionalism approach, coincide with Villegas' (1988) concept of the "aesthetic of the useful" (p. 15), opposed to the idea of a "beauty of the pretty" (p. 16), merely based on subjective and aesthetic culturally influenced codes. This conception of the beauty serving functionality was previously exposed and defended by Pulos (1983), proposing that "No principle of design in America is so strong as that an object achieves beauty to the same degree to which it serves its function" (p. 7). According to the author, there was a tight relation between the notion of beauty and function from the very beginning of colonization, relegating beauty as "(...) the natural by-product of functional refinement"
(Pulos, 1983, p. 7), as an inherent and inseparable value, derived from the product's efficiency.

Based on Eames \& Eames' concepts, regarding functionality over aesthetics and luxury, Steinberg (2017) questions "what is the core purpose and the essential experience that the highly ornate tabernacle is supposed to fulfill and bring about, and what is it that all the embellishment and ornament are meant to celebrate?" (para. 5), inquiring about the prioritization of decorative excesses and unnecessary ornaments surrounding everyday utilitarian implements and proposing the concept of a "(...) way back to the core purpose and essential experience (...)" (Steinberg, 2017, para 5.), a return to the basic problem-solving, exemplified in the custom of implementing corn husks and leaves from diverse plants, including banana, plantain (Figure 3 ) and bijao (Calathea panamensis), usually found on riverbanks, recognized by its large, thin, pleated leaves (Figure 4) used as an eating surface and packaging material in rural peasant societies

Figure 4. Bijao plants (Calathea panamensis), also known as Heliconia Bihai. Bijao leaves are used as a natural package for assorted traditional foods. Cali, Colombia.

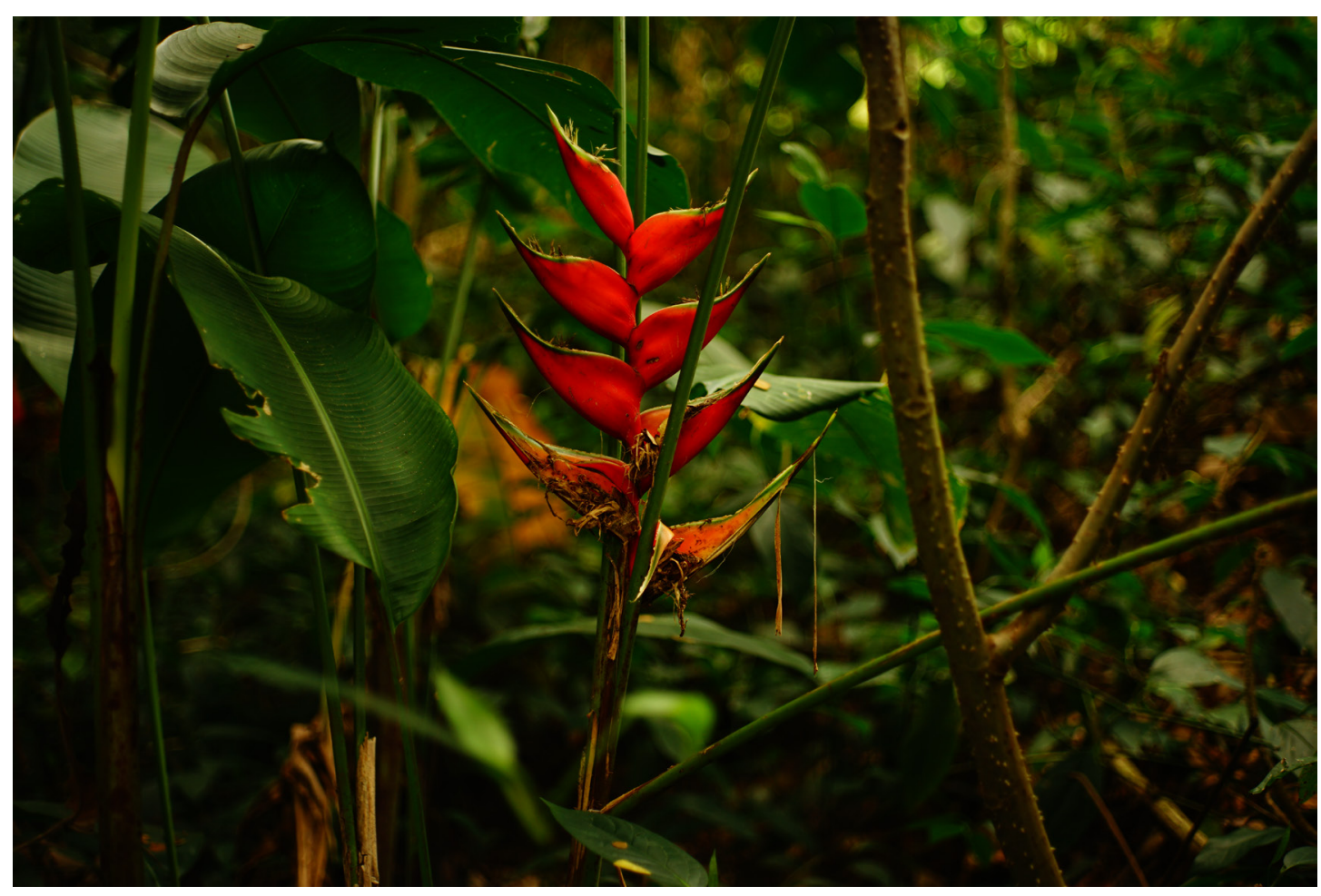

Source: own elaboration, 2020. 
in America (Müller-Schwarze, 2006). The use of these natural resources as a cooking and alimentary implement, despite social classes, castes, or creeds is referred to by Eames in his Banana leaf parable, which would be the base for an eponymous unfinished and unreleased documentary movie (Eames \& Eames, 1972).

\section{Beyond Aesthetics and Functionality}

The natural texture of his materials and the honest marks of his tools were ornament enough for the settler. The fingerprint in the clay, the scar of the adze on the wooden beam, the facets of the hammer on the metal, and the warp and weft of the loom all provided the democratizing link that bound maker and consumer to product (Pulos, 1983, p. 7).

According to the author, these natural textures, and honest surfaces, including fibers, leaves, woods, and assorted minerals (Figure 5, Figure 6, Figure 7, and Figure 8), carry a deeper symbolic meaning, beyond functionality, aesthetics, or visual entertainment, adding a human and spiritual significance to handcrafted everyday artifacts, associated to their handcrafted production. As explained by Pulos (1983), "the spare utilitarian objects and unsophisticated folk arts of the rural colonists were often demeaned by the patricians of America and England as 'country made' and therefore devoid of aesthetic value" (p. 10); however, colonists' buildings and furnishing were embracing an emerging democratic art form, portraying a simple elegance through their implements and a direct innocence through their signs and symbols. Following a similar approach, Rousseau, and other contemporary European social philosophers, (as cited in Pulos, 1983), were proposing that "(...) only a return to the natural man and a simpler way of life would rid civilization of its distortions and release anew those primary virtues upon which a good and sound society depends" (p. 10), while these theories were established to test intuitively by colonists in the distant American wilderness and settlements.

"The elder women remember many cooking utensils made from plant materials; nowadays, members of the younger generation are gradually replacing such with non-plant materials" (MüllerSchwarze, 2006, p. 326); as the author explains, due to modernization and industrialization, traditional organic resources have been displaced and replaced with synthetic industrialized materials in rural communities, as ancestral alimentary related customs, including traditional cooking and packaging practices, are relegated. Regarding our modern and globalized context, is exposed by García-Canclini (2002), “(...) globalization tends to uniform the market and standardize common patterns (...)" (para. 8) “(...) pretending to homogenize or subordinate local markets and cultural forms under a worldwide self-proclaimed project (...)" (para. 2), being necessary to appreciate the differences, juxtaposing this standardizing impact. Globalization's homogenizing effects may affect and threaten everyday artifacts and practices, having an impact on everyday things and product design, as Villegas (1988) states:

\section{(...) these days, the advances on communica- tions, media and technological concentration grow every single day, tending to standardi- ze the object universe. Therefore, traditional identities start disappearing or become unno- ticed, due to diverse reasons, as the absence of a solid and proper cultural tradition -after the disappearance of the indigenous culture and the adaption process of the European- distancing us from our own self (p. 7).}

As expressed by Eames (2007), “(...) one can judge the state of culture in a country by the quality of the bread and soup" (p. 226), stating that alimentary heritage and traditional foods may be considered as a testimony of a society's identity, folklore and idiosyncrasy, as exemplified by Figure 5, Figure 6 and Figure 7. This conception, regarding traditional and popular products, was anticipated by Eames \& Eames (1957a) in their Day of the Dead documentary, using traditional decorative, utilitarian, and ceremonial objects, as a representation of a country's folklore, beliefs, and spirituality, especially in rural contexts and peasant communities.

According to García-Canclini (2005), "Folklore is constituted by a series of traditional goods and cultural forms, mainly of an oral and local character, that are always unalterable", as it repre- 
Sociedad y Economía N 42 (Ene - abr 2021) / e-ISSN: 2389-9050

The Banana Leaf Approach: An Appreciation of Utilitarian Handcrafted Artifacts in the American Context

Figure 5. Natural wicker fibers are transformed into handcrafted utilitarian baskets. Latacunga, Ecuador.

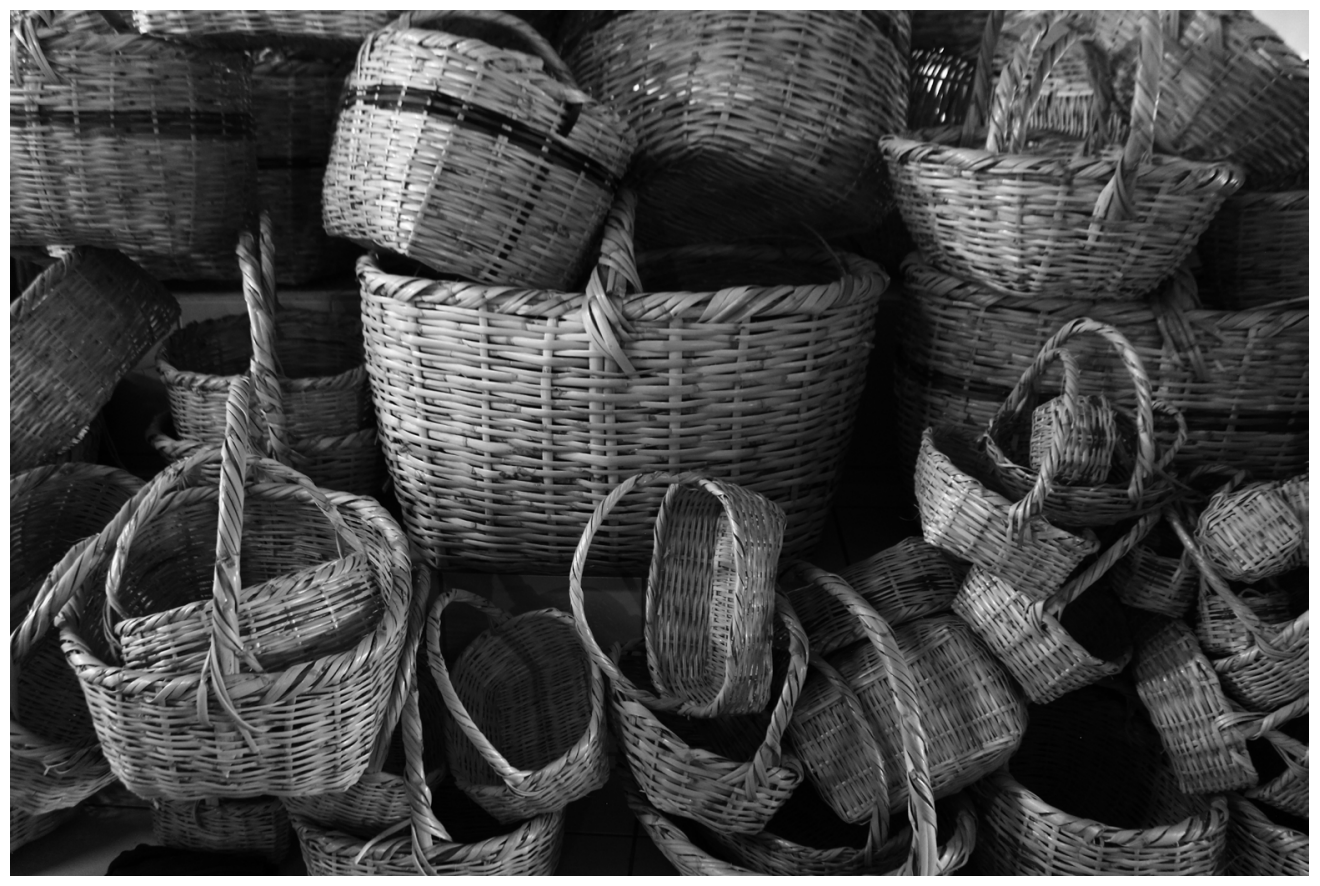

Source: own creation, 2018.

Figure 6. Natural vegetable fibers are transformed into utilitarian handcrafted espadrilles and home artifacts for peasants and farmers. Pasto, Colombia.

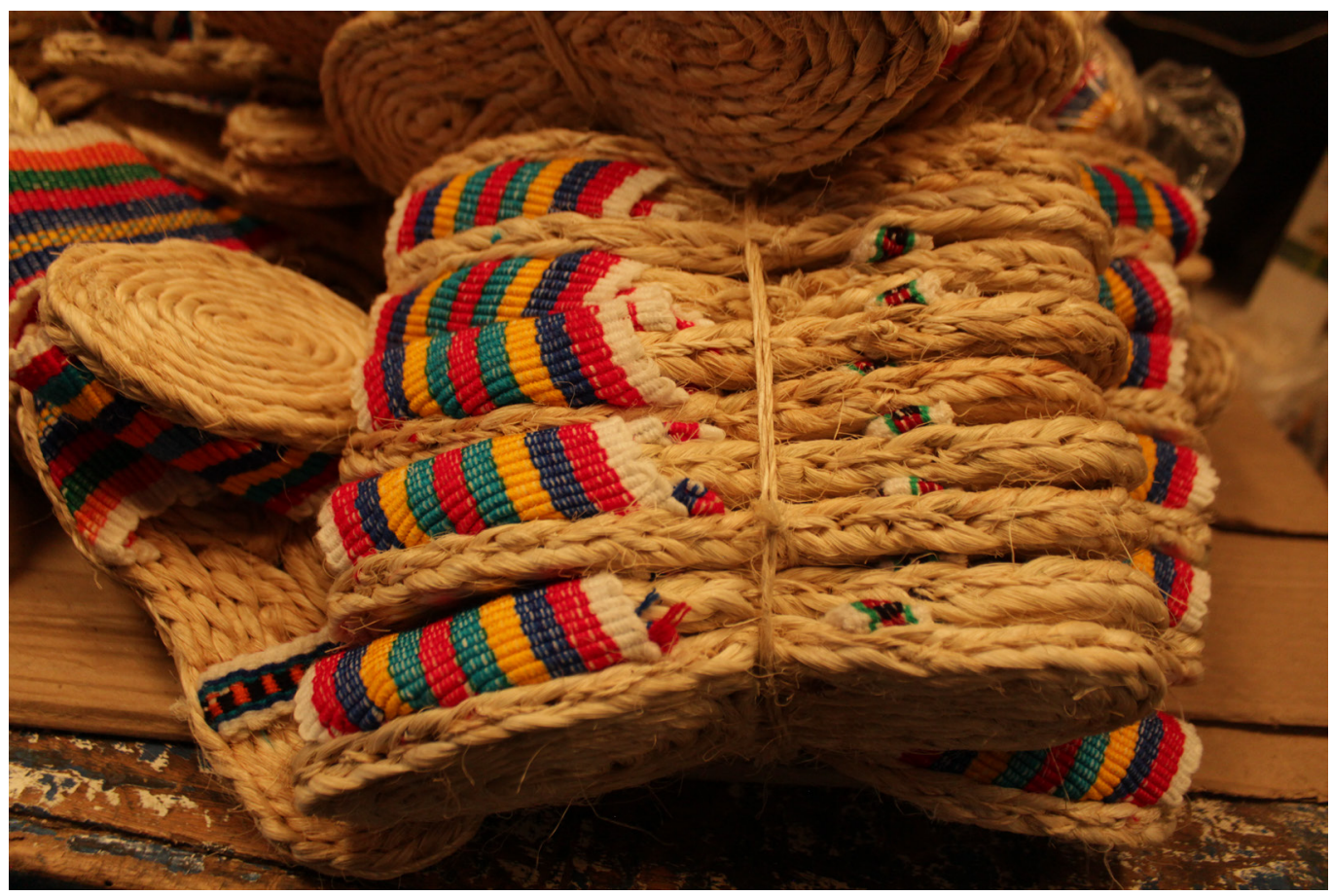

Source: own creation, 2018. 
Sociedad y Economía N`42 (Ene - abr 2021) / e-ISSN: 2389-9050

Rafael Ángel-Bravo

Figure 7. Traditional handcrafted artifacts are commercialized through popular and rural markets. Latacunga, Ecuador.

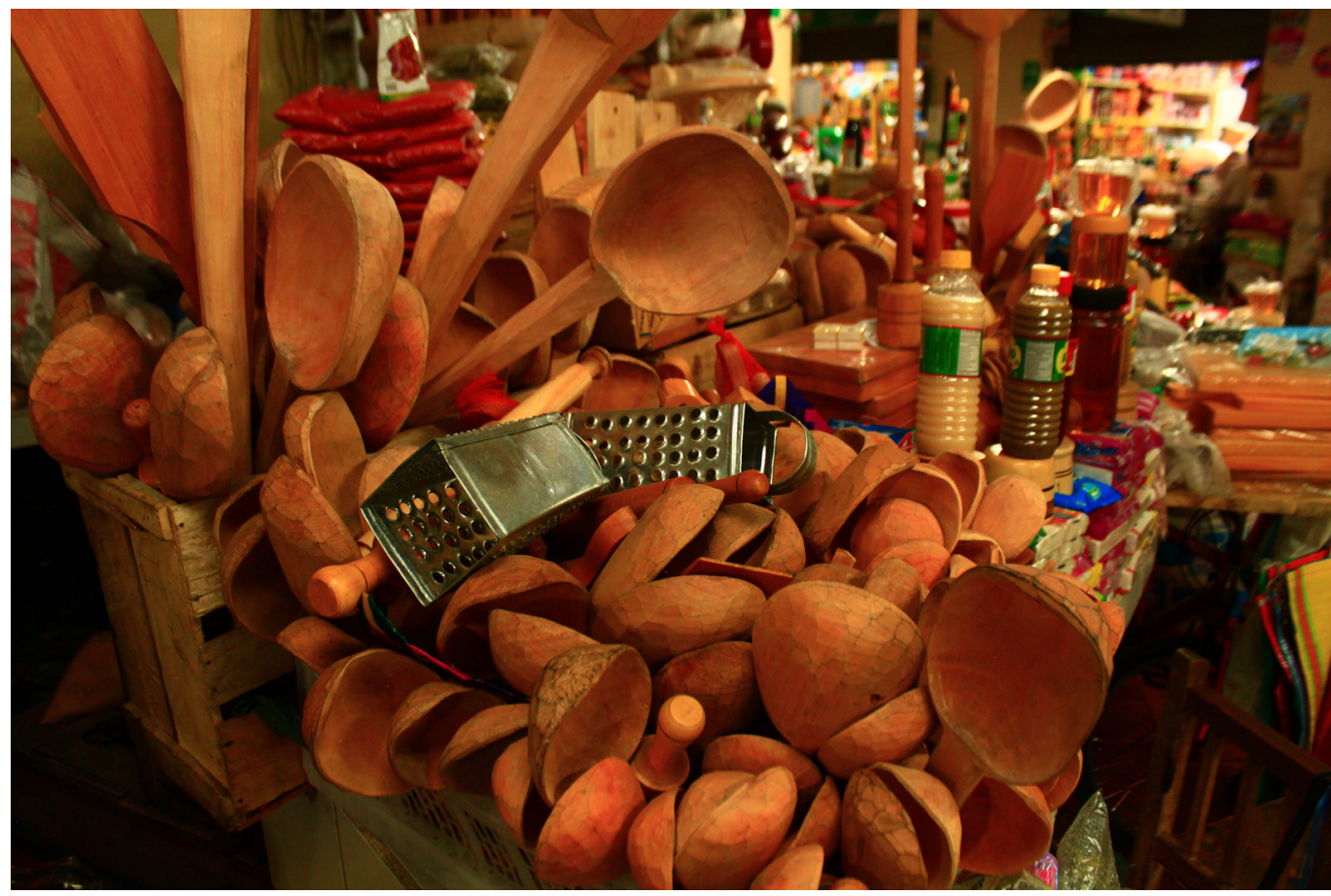

Source: own creation, 2018.

Figure 8. Assorted foods are packaged and served in banana leaves. Silvia, Colombia.

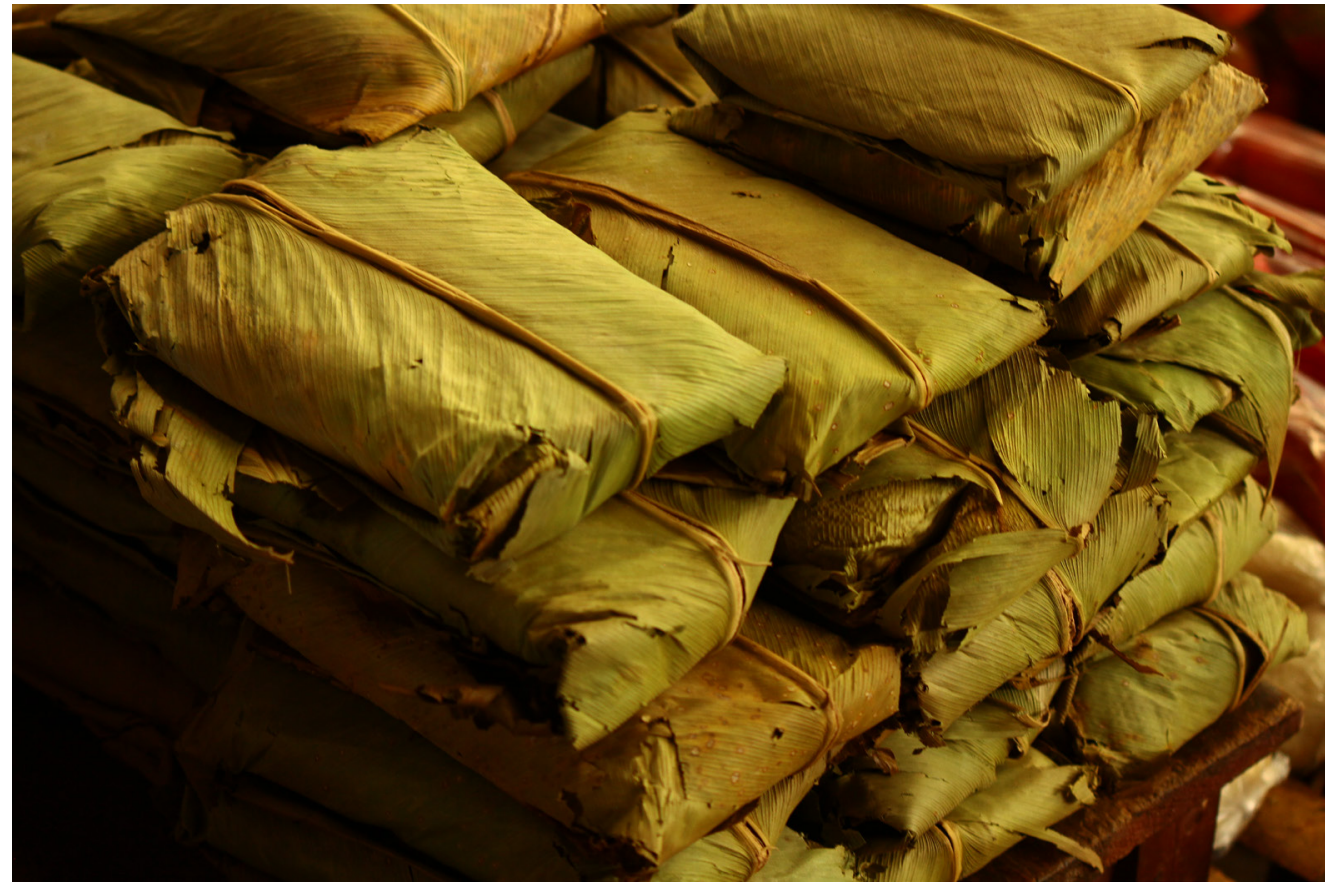

Source: own creation, 2017. 
sents "(...) the essence of the identity and the cultural patrimony of each country" (p. 152); as proposed by the author, modernism, globalization, mass media, migration and other cultural phenomena, strongly influence folkloric expressions, as they have transcended and developed, from a closed, archaic and rural universe, to hybridized and urbanized modern societies.

As explained by Abadía-Morales (1983), the concept of folklore is proposed in 1846, by the anthropologist William John Toms, to define the popular knowledge, every traditional, anonymous, and empirical expression, what a society or community believes, says, thinks, and does. Taxonomically speaking, as stated by the author, folkloric expressions can be classified into four different categories, as follows:

\section{* Literary folklore \\ * Musical folklore \\ * Choreographic folklore \\ * Demosophical folklore}

This last category mainly includes different rather functional products, including decorative and handcrafted tools, artifacts, alimentary tradition, and medicine, among others. Handcraft, as a crucial example of demosophical folklore, is defined by Abadía-Morales (1983) as the artistic and utilitarian crafts, mostly limited to family environments and primitive domestic workshops, evolving from indigenous origins and contexts to peasant and agrarian communities, eventually transcending to urban detribalized populations and industrialized processes. Handcraft production involves cookware, utilitarian home artifacts, furniture and tools, decorative implements, artwork, dress, toys, hats, musical instruments, accessories, bags, and assorted related objects (Figure 1, Figure 2, Figure 5, Figure 6 and Figure 7). As Villa-Carmona (2005) explains, artisan communities expect handcrafted products' function and usability to be as simple and basic as the natural resources involved in their genesis; additionally, these artifacts are expected to transcend and survive through time, against any form of obsolescence, staying usable as they strengthen an emotional bond, based on tradition and longevity.

As explicated by Ocampo-López (1981), these folkloric expressions and practices are inherited by orality between societies and generations, considered anonymous as their origins are diluted in time and survive through the 20th century, despite globalization and industrialization, struggling to resist the impact caused by these processes, which tend to homogenize markets and cultural diversity.

\section{The Uncommon Beauty Beyond Form and Function}

Even though architects Charles and Ray Eames were developing successful design careers and their individual legacies, constituting a collaborative design team, took their possibilities and potentials to a new level, beyond the mere and simple problem resolution or the satisfaction of human needs, within consumerist society. Proposing a design team, boosted their possibilities, transcending through new creative fields such as textile design, theoretical production, and documentary films, which finally lead to a renewed conception about design, beyond the form-versus-function debates that arise from industrialization and subsequent movements, such as Arts \& Crafts, De Stijl, and Bauhaus, among others.

Eames \& Eames' documentary visual works like Bread (Eames \& Eames, 1953), Day of the dead (Eames \& Eames, 1957a), Tops (Eames \& Eames, 1969) and Banana Leaf (Eames \& Eames, 1972), as Koenig (2015) explicates, use "(...) daring combinations of real images, quick montages, animation and still shots, designed to catch the viewer's attention and spread information" (p. 69) An exploration regarding the traditional and folkloric valuation of common and everyday objects, gets materialized through their Day of the Dead documentary short film, exploring the prominent role of religious images, assorted spiritual symbols, and objects, within this traditional and ancestral celebration, that integrates spirituality, omen, superstition, 
religious beliefs, and joy, focusing on the inherent significance and symbolism of objects, associated to these ceremonies, over their followers and practitioners, specially within rural communities (Eames \& Eames, 1957a). Besides displaying an extensive sample of ritual-associated products, objects, and toys, this documentary project highlights the handcrafted production process behind some pieces, adding or evidencing a human factor, to these symbolic artifacts, from an artistic perspective.

On a similar approach, through their Tops short film, Eames \& Eames explore a different dimension concerning the estimation of things, the interaction between toys and users and the cultural importance of handcrafted artifacts, exalting spinning top toys beyond their merely functional entertaining purpose, as an object that acquires a popular culture status and becomes a part of people's lives and memories, collective imaginary and popular culture (Eames \& Eames, 1969). As proposed by Eames \& Eames (2015) "Toys are really not as innocent as they look... Toys and games are the preludes to serious ideas. Electricity was a game first before it became a source of power" (p. 219). Through their extensive filmography, including works like Bread (Eames \& Eames, 1953), Toccata for Toy Trains (Eames \& Eames, 1957b), Day of the Dead (Eames \& Eames, 1957a), and Tops (Eames \& Eames, 1969), the Eames team evidence their interest in toys, artifacts, and foods, as a cultural and traditional element, exalting their symbolic and emotional significance for society, beyond their mere aesthetics or functionality. Including architecture, industrial design, product design, photography, and movies, these artists' collaborative efforts helped propose a new vision about the appreciation and the importance of utilitarian everyday objects in people's lives. Understanding the importance of these artifacts as a crucial protagonist of popular culture and folklore, achieving in some cases an iconic status in pop culture and transcending through time as a sample of a society's omen, beliefs, superstition, spirituality, and imaginary, which relegates beauty and efficiency to a secondary place in the appreciation that individuals may have, regarding their common everyday artifacts.

\section{The Banana Leaf Approach}

The human being as homo faber, as an architect, has applied his intelligence to create functional implements, necessary for his existence, adapting assorted techniques to the manufacture of innovative objects, according to his everyday problems, needs, and evolution. Starting with stone arrows, axes and various hunting and cooking artifacts, to more complex forms of utilitarian, decorative and symbolic pieces of handcraft, as the author explains, peasant ancestors had the knowledge and developed the skills necessary to transform their environment, raise the animals, cultivate the land and produce their artifacts, taking advantage of the tranquility of their homes and making responsible use of the natural resources that the environment offered. Besides farming, rural societies produced assorted handcrafted solutions for their daily activities, kitchen artifacts, and containers, as well as ornamental objects, musical instruments, and religious symbolic paraphernalia (Villegas, 1988). With the development of agriculture, assorted kinds of settlements were stablished, and it was necessary to save, protect and preserve alimentary resources for their later consumption, so agrarian societies solved the problem of packaging many products, especially food, through the use of the leaves of some plants to protect the products obtained from others, receiving from nature the packaging required to preserve their production (Díaz-Piedrahíta, 1981).

As Ocampo-López (1981) explains, the historical evolution of societies is determined by the adaptation of the human being to the geographical environment as colonists and peasants are equally dependents of "(...) the relief, the climates, the vegetation, the crops, the animals, the populations and a slowly built geographical balance (...)" (p. 7), from which they cannot deviate. According to the author, human displacement and migration through the mountains, conformation of rural communities and villages, human settlements in coastal areas, and the geographical framework of the civilizations, determine long-lasting collective conceptions and mentalities, motivating the configuration and reconfiguration of cultural identities and the construction of popular beliefs, from nature, the spiritual world and society. 
As stated by Pulos (1983), the spartan conditions in the wilderness and the new settlements of America, forced the colonists to adapt to these hostile environments and "(...) avoid the devotion to rich detail and elaborate ornament that served in the older aristocracies to exaggerate the value of products through the extravagant consumption of energy" (p. 7). According to the author, "The challenge of survival in the New World, including the clearing of the wilderness and the building of a home, encouraged inventiveness and demanded versatility" (Pulos, 1983 , p. 6), leading to a new utilitarian conception regarding everyday tool and artifacts, generating creative and simpler solutions to the colonists' daily problems and basic needs.

Plant knowledge has been a fundamental skill for peasant and artisan societies throughout history: rural populations in the American context use assorted leaves and husks as a boiling device for traditional everyday recipes, foods are commonly wrapped and carried in natural materials, resources like woods, dry fruits, seeds, husks have been an essential material for decorative and utilitarian artifacts, whether used for commercial trade or to resolve innumerable day-to-day problems (Müller-Schwarze, 2006).

As described in the classification originally proposed by Díaz-Piedrahíta (1981), the multiplicity of uses of leaves in the alimentary context, can be categorized into four groupings: "(...) those used to wrap raw foods; those used to wrap food during its preparation process; those used to pack and protect food once it is prepared, and those used to transport and protect food in condition of crop loading" (Estrada-Ochoa, 2020, p. 34). In the American context, since the arrival of Christopher Columbus, when European conquerors and colonizers arrived to America, they discovered a wide variety of foods prepared and wrapped in leaves. For the indigenous communities of the American continent, these resources were more than just a wrapping material for foods, since leaves could be used as a cooking implement, they could add particular flavors to the aliments, function as a natural packaging for alimentary preservation, or even be used for significant rituals in the lives of indigenous people, including childbirth, funerals, and sacrifices, as described by Agamez \& Pinto (2020).

The use of natural leaves as a surface for meals or a wrapping material for miscellaneous aliments motivates a reflection about functionality over decorative extravagances, futile shapes, and luxuries considering the industrial design and the conception of everyday projects. The banana and plantain leaves become a great example of how consumers in rural contexts have adapted and used the resources of their natural environment, looking for the most simple and efficient solutions for their everyday needs and activities. These organic structures have worked as a surface and an artifact to serve, wrap, and carry different kinds of foods through different countries and cultures around the world (Figure 3, Figure 4, Figure 8, and Figure 9).

Describing the use of the banana leaf as an eating container, Put Chutney (2015) points out the benefits of this custom, describing it as an ergonomic experience, describing these implements as "(...) unapologetically traditional, 100 percent natural, fully recyclable, easy to use, and easy to dispose (...)" (0:40), as a source of psychological satisfaction and a celestial experience, involving touch, sight, and taste, into a multisensorial perception. In India, as stated by the author, there's a holistic practice involved within the action of eating from a banana leaf, using their fingers instead of artifacts like spoons, forks, and knives, implicating a direct contact with food. This process allows the possibility of gauging the texture and temperature of the aliments, motivating a distinctive user experience, as a synaesthetic perception.

Through a series of speeches, between 1970 and 1971 (as cited in Koenig, 2015, p. 83; Steinberg, 2017), Eames described his experience in India using this short story, commonly known as The parable of the banana leaf:

In India, the poorest, those lowest in caste, eat very often off of a banana leaf. Those a little bit up the scale eat off of a sort of low-fired ceramic dish. And a little bit 
Figure 9. Banana and plantain leaves are used as a surface and packaging material for assorted foods. San Andrés, Colombia.

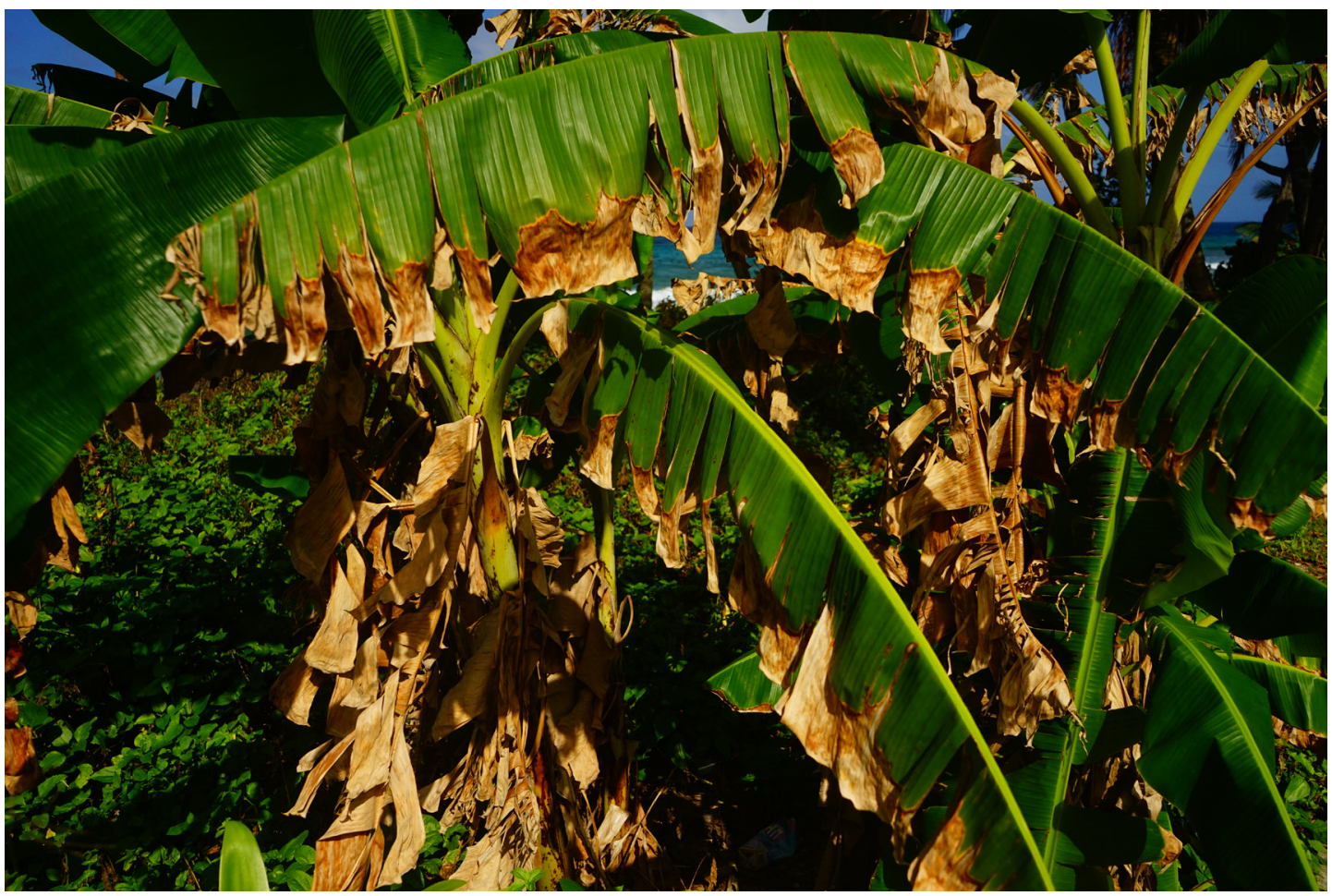

Source: own creation, 2020.

higher, why, they have a glazed platter, a thing they call a thali. And there get to be some fairly elegant glazed thalis, but it graduates, if you're up the scale a little bit more, to, why, a brass thali. And a bell-bronze thali is absolutely marvelous, it has a sort of ring to it. And then there are things like silver-plated thalis, and there are solid silver thalis, and I suppose some nut has had a gold thali that he's eaten off of, though I've never seen one. But you can go beyond that, and the guys that have not only means but a certain amount of knowledge and understanding go the next step, and they eat off of a banana leaf (para. 2).

As exposed by Koenig (2015), this traditional parable explained India's caste system and was frequently used by Eames, to describe relativity of values in people's lives and relationships with objects; defined by the author as "the simplest and most refined container for food" (p. 83), banana leaf constitutes the ultimate example of minimalism and functionalism on problem-solving, about the way con- sumers interact with their aliments and everyday activities. Considering diverse conceptions concerning this parable, the banana leaf could be understood as a symbol of minimalism and functionalism, as a representation of tradition and cultural resistance facing the effects of homogenizing effects of modernity and globalization, or the idea of transcending into an nonmaterialistic spirituality, as the consumer frees himself and strips his life from unnecessary ornaments, material luxuries or futile material possessions.

The banana leaf as a packaging and serving implement constitutes the epitome of functionalism in its purest form, an essential example regarding the idea of natural textures and honest surfaces, as proposed by Pulos (1983), reaching a deeper symbolic meaning beyond functionality and aesthetics, adding a human and spiritual connotation to the alimentary process, providing a democratizing essence, increasing the bond between the consumer 
and the product, as the social gaps disappear as implied by Eames (1972), motivating a holistic and celestial experience, as defined by Put Chutney (2015). Using assorted leaves as a packaging material for miscellaneous foods could be considered as a basic example and the purest form of euthenics within rural communities, as a traditional alimentary practice that evidence how individuals adapt and take advantage of the natural resources available, while the ergonomic, experiential and alimentary process, gives the consumer an experience beyond efficiency and aesthetics, while the alimentary ritual itself achieves a cultural, traditional, symbolic, emotional, ritual, mystical and spiritual significance.

\section{Conclusions}

Through the history of mankind, especially in rural contexts and peasant societies, individuals have been forced to adapt to the natural conditions, circumstances, and environments, transforming spaces and materials, developing creative solutions for their everyday problems and needs, taking advantage of the natural resources available (Figure 10). This adaptation processes lead to a transformation of plants, fibers, leaves, woods, and assorted materials, into handcrafted utilitarian artifacts, decorations, religious paraphernalia, and other solutions for their routine activities and practices including hunting, cooking, dress, superstition, omen, and festivities; therefore, these objects can fulfill a purpose other than the basic needs of the community, to achieve a valuation or appreciation beyond aesthetics or efficiency.

Within rural and wild settlements, the practice of euthenics, as defined by Pulos (1983), has transformed users into designers and builders of their everyday tools and artifacts, as individuals are forced to adapt to the hostile conditions of the new natural environments, after migratory and colonization processes. Developing euthenics, colonists improved their new American settlements, transforming the natural conditions and resources of the wilderness,

Figure 10. Peasant merchants trade their products in rural, peasant, or central markets. Silvia, Colombia.

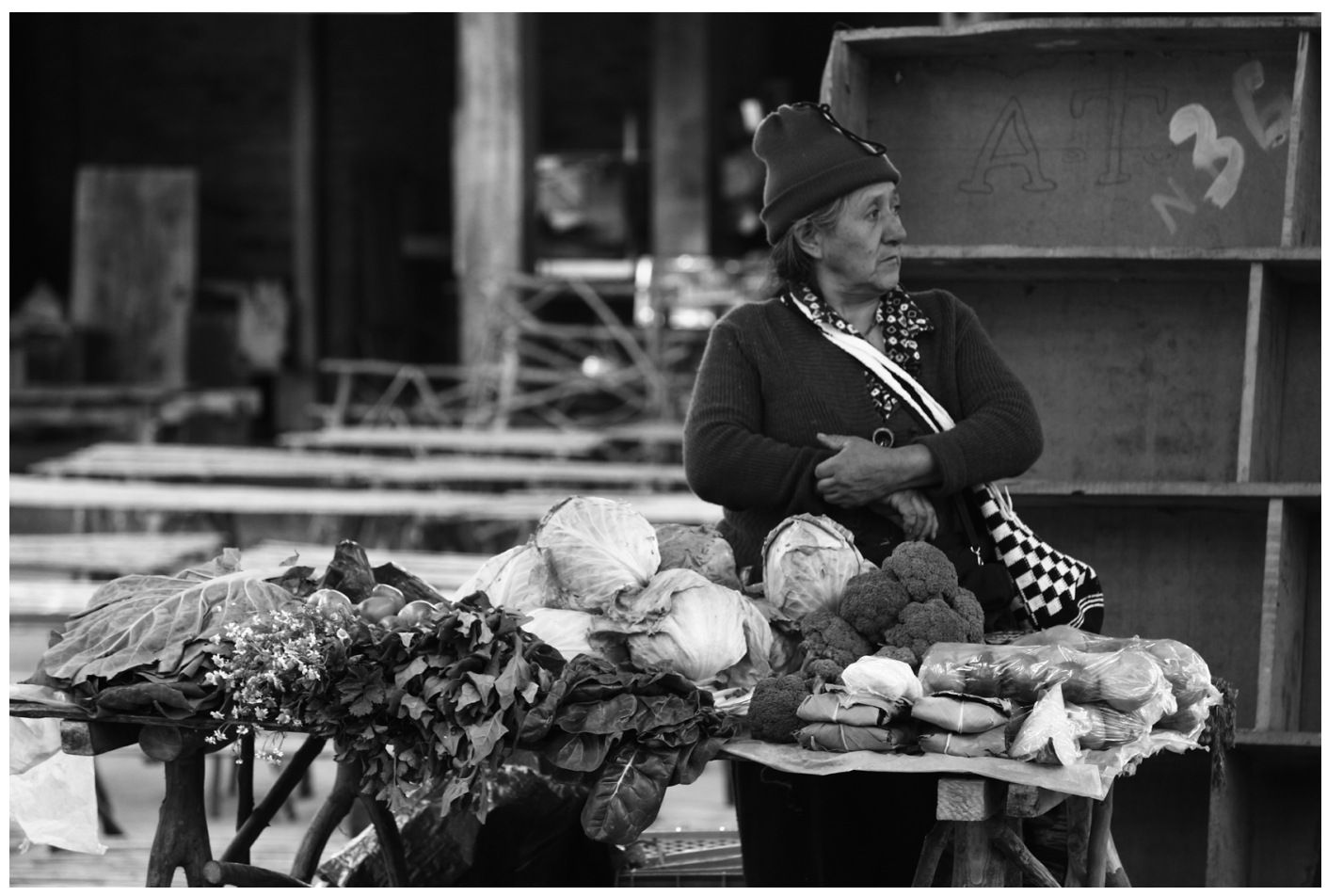

Source: own creation, 2017 
satisfying their primary needs, facilitating their new lives in these unknown territories and solving their everyday problems, comprehending the consumer and the inventor as a unified entity, as the human being takes advantage of the time and resources to become an artisan. Farmers and peasants initially provide solutions for their communities and eventually find a space for the commercialization and barter of some of these products within popular or rural markets, exemplified in Figure 10 and Figure 11 .

Described by Estrada-Ochoa (2020) as evidence of America's aboriginal and pre-Columbian heritage, the use of banana, bijao, corn, and assorted plants as a natural and organic source for packaging and serving materials, must be considered as a fundamental example of these traditional and ancestral practices, as it demonstrates how consumers can transform natural resources from their environment, into functional artifacts, tools, and miscellaneous implements, responding to their primary needs and everyday problems. Beyond aesthetics and efficiency, these products achieve a traditional, democratizing, spiritual and folkloric significance, as they transcend through different cultures, generations, castes, or social strata, reducing social gaps, stimulating a stronger bond and a closer involvement, embracing a holistic, multisensory, and synaesthetic experience, involving the consumer, the product, and its container.

Honest surfaces and natural materials give the handcrafted tools and products an added value beyond their benefits, functionality, or efficiency (Figure 11); as proposed by Eames \& Eames, through their extensive documentary work, common day things and utilitarian objects' beauty goes way beyond subjective aesthetical perceptions, as their importance is strongly attached to their functionality for rural societies' everyday activities and sometimes associated to spiritual, religious, cultural and traditional customs. These products become an essential part of people's lives, traditional folk knowle-

Figure 11. Natural vegetable fibers are transformed into traditional hats and handcrafted utilitarian artifacts for farmers and local consumers. Pasto, Colombia.

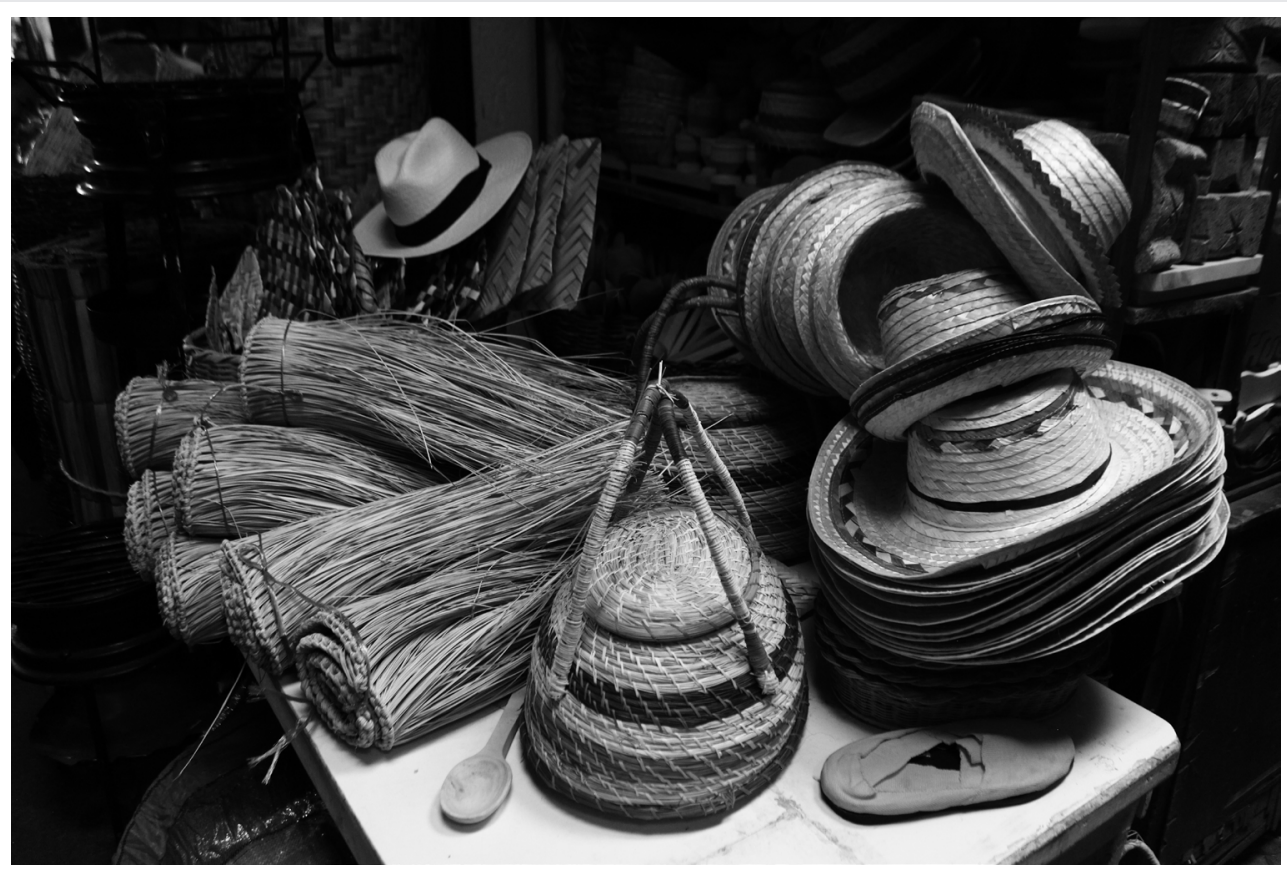


dge, and popular culture, telling the story of the American continent's transformation, from rural and agrarian societies to urban industrialized communities. Handcrafted artifacts have been an essential part of people's lives and the evolution of civilizations, facilitating practices such as hunting, farming, cooking, eating, cleaning and farming, as they have served the human being, improving his daily labor and satisfying his basic needs; additionally, these objects' handcrafted nature has contributed an additional meaning to artifacts and ornaments as they achieve a special character, supported by their inherent human factor.

From the participatory design processes developed by the colonists in the new American settlements to the collective appropriation of these objects, spaces, and products in peasant and agrarian societies, there's a collective approach regarding the way these works are conceived and how they are embraced by communities, as fundamental solutions for everyday needs and problems, eventually reaching an iconic and traditional status in folklore, popular culture and heritage, that can only be achieved through a series of organic, participatory, implicit and unwritten social agreements surrounding an object, a practice, a belief or a custom, within a determined geographic, social or cultural context, as they are collectively embraced by a community or a group of people, delivered and inherited generationally through orality. Charles and Ray Eames' audiovisual work and theories, emphasize the idea of beauty and efficiency as indissoluble principles regarding utilitarian artifacts, and how these objects may achieve a new dimension beyond these factors, as they transcend through oral tradition to achieve a symbolic, spiritual, ritual or even iconic status for a community, a territory, a country or a whole culture, as a crucial component of their tangible and intangible heritage, identity and folklore, especially in rural contexts and artisan societies, through North, Central, and South America.

\section{References}

Abadía-Morales, G. (1983). Compendio General del Folklore Colombiano (4 ed.). Banco Popular.

Agamez, C., \& Pinto, H. (2020). Envueltos de plátano, yuca y maíz en las cocinas tradicionales de Colombia. Hambre de Cultura.

Cruger, R. (2012). The Eames'Appreciation of the World Through Common Objects. https://www.treehugger. com/culture/eames-appreciation-world-through-common-objects.html

Díaz-Piedrahíta, S. (1981). Las hojas de las plantas como envoltura de alimentos. Ediciones CIEC.

Eames, C. (2007). 100 Quotes by Charles Eames. Eames Office.

Eames, C., \& Eames, R. (1953). Bread (Short film). https://www.eamesoffice.com/blog/film-bread-carlahartman/

Eames, C., \& Eames, R. (1957a). Day of the Dead (Short film). https://www.youtube.com/watch?v=YJZf$2 \mathrm{fLpGM} \& \mathrm{t}=185 \mathrm{~s}$

Eames, C., \& Eames, R. (1957b). Toccata for Toy Trains (Short film). https://www.youtube.com/ watch?v=oorg2q0D8hs

Eames, C., \& Eames, R. (1969). Tops (Short film). https://www.youtube.com/watch?v=UJ-VFMymEiE

Eames, C., \& Eames, R. (1972). Banana Leaf (Short film). https://www.imdb.com/title/tt0286481/

Eames, C., \& Eames, R. (2011). Eames' Words: The Guest Host Relationship. Exhibition at the Architecture + Design Museum, Los Angeles. https://www.eamesoffice.com/blog/eames-words-at-the-a-d-museum/

Eames, C., \& Eames, R. (2015). An Eames Anthology. Yale University Press. 
Sociedad y Economía N 42 (Ene - abr 2021) / e-ISSN: 2389-9050

Rafael Ángel-Bravo

Estrada-Ochoa, J. (2020). Origami criollo: Sabor y belleza de la cocina en hoja. Boletín Cultural y Bibliográfico, 54(98), 32-43. https://publicaciones.banrepcultural.org/index.php/boletin_cultural/article/view/20976

García-Canclini, N. (2002). Entrevista con Néstor García Canclini I. La Iniciativa de Comunicación. http:// www.comminit.com/la/node/67260

García-Canclini, N. (2005). Hybrid cultures: Strategies for entering and leaving modernity. University of Minnesota Press.

Hogarth, W. (1753). The analysis of beauty. Reeves.

Koenig, G. (2015). Charles \& Ray Eames. Taschen.

Müller-Schwarze, N. K. (2006). Antes and Hoy Día: plant knowledge and categorization as adaptations to life in Panama in the twenty-first century. Economic Botany, 60(4), 321-334. https://doi.org/10.1663/00130001 (2006)60[321:AAHDPK]2.0.CO;2

Ocampo-López, J. (1981). El folclor y los bailes típicos colombianos. Biblioteca de escritores caldenses.

Pulos, A. J. (1983). American Design Ethic. MIT Press.

Put Chutney (2015). South India 101 - The Banana Leaf. https://www.youtube.com/ watch?v=OqWsafUmzSE\&t=40s

Steinberg, R. J. C. (2017). The Banana Leaf, and Sanctuary. HuffPost. https://www.huffpost.com/entry/thebanana-leaf-and-sanctuary_b_58c24ee5e4b0c3276fb7836e

Villa-Carmona, G. (2005). Diseño, sistema productor de sentido. Revista Kepes, 2(1), 7-14. http://kepes. ucaldas.edu.co/downloads/Revista1_2.pdf

Villegas, L. (1988). Arte Factos: Elementos de la vida cotidiana del Viejo Caldas. Villegas. 